\title{
Triple Band Parasitic Array Antenna for C-X-Ku-Band Application Using Out-of-Phase Coupling Approach
}

\author{
Anubhuti Khare and Rajesh Nema \\ University Institute of Technology Rajiv Gandhi Proudyogiki Vishwavidyalay, Bhopal, India \\ Correspondence should be addressed to Rajesh Nema; rajeshnema20018@gmail.com
}

Received 21 March 2014; Revised 15 May 2014; Accepted 4 June 2014; Published 3 September 2014

Academic Editor: Wenxing Li

Copyright ( 2014 A. Khare and R. Nema. This is an open access article distributed under the Creative Commons Attribution License, which permits unrestricted use, distribution, and reproduction in any medium, provided the original work is properly cited.

Triple band parasitic array antenna for $\mathrm{C}-\mathrm{X}-\mathrm{Ku}$-band application is presented. The proposed antenna is designed using the concept of parasitic array and out-of-phase coupling approach. The objects of research are to optimize total inductance of geometry by using out-of-phase inductance approach. The out of phase inductance of geometry consists of using two U-patches novel director on the left side of geometry, appropriate dimension of ground plan, and gap coupling between parasitic and active patches. The dimension of the ground plan geometry is $0.5 \lambda$ mil $\times 0.5154 \lambda$ mil. The usable impedance bandwidth of design antenna is " $5.8 \mathrm{GHz}$ to $18 \mathrm{GHz}$ " (102\% impedance bandwidth) and gain enhancement is up to $11.8 \mathrm{dBi}$. The proposed antenna can be used for X-Ku band and C-band applications. Both simulated and measured results are presented, which are in good agreement. The proposed antenna was fabricated with a thin copper layer printed on a thin lossy FR4 substrate for low-cost production.

\section{Introduction}

An explosive growth of the wireless radio a communication system is currently observed in the microwave band. In [1], a dual-frequency antenna based on the Sierpinski fractal with two parasitic patches to enhance the impedance bandwidth was presented. An electrical circuit model is formed by RLC resonators to learn about the antenna physical behaviour and to achieve the dual band operation minimizing a trial-and error numerical/measurement proofs. The antenna designed, using a method of moment, obtained two bands with a broad bandwidth and similar radiation patterns. In [2], a triple-frequency antenna is designed having a dual-band and monoband antenna with broadside radiation patterns. The dual-band antenna is inspired in the Sierpinski fractal. Such a dual-band antenna is stacked over a monoband antenna. The antenna presented a broadband behavior at each band using parasitic patches. The antenna is designed using a MoM commercial code, obtaining three bands with a broad bandwidth, high efficiency, and similar radiation patterns. Huang et al. [3] presented a microstrip antenna design that effectively circular polarized (CP) and suppressed harmonics. By modifying the size and position of two peripheral cuts, two orthogonal modes that have equal amplitude and are 90 out of phase were simultaneously excited. The four rightangle slits embedded in the antenna can block the secondand third-order harmonic signals. The adopted CP antenna built on a low-cost FR4 substrate measured bandwidth of $137 \mathrm{MHz}$ (10-dB return loss) and a 30-MHz CP bandwidth (3$\mathrm{dB}$ axial ratio). This work is further extended in [4] where a triband dual-polarization (TBDP) shared aperture microstrip array antenna is designed for synthetic aperture radar (SAR) application. It operates in L-S-X Bands with a frequency ratio of $1: 2.8: 8$. This TBDP shared aperture array is assembled by two L/S and L/X DBDP shared-aperture sub arrays with one L-band dual-polarized sub array, which exhibits wide impedance bandwidth of $13.4 \%, 14.8 \%$, and $16.8 \%$ in L-S band and X-bands. Usable bandwidth of design antenna is further modified in [5], a printed wide-slot antenna with a parasitic patch for bandwidth enhancement, which is $80 \%$ for $|\mathrm{S} 11| \leq-10 \mathrm{~dB}$ ranging from " $2.23 \mathrm{GHz}$ to $5.35 \mathrm{GHz}$." Work further carried in [5-8], in [8] presented a novel compact ultra wideband (UWB) printed slot antenna with three extra bands for various wireless applications. The low-profile antenna consists of an octagonal-shaped slot fed by a beveled and stepped rectangular patch for covering the UWB band 
(“3.1 GHz-10.6 GHz”). In [7], a new design of a compact ultra wideband (UWB) antenna with multiple bands notched characteristic utilized a C-shape ground to realize miniaturization and two mushroom-type electromagnetic band gap (EBG) structures to create notched bands. The antenna achieved an operation frequency band from " $3 \mathrm{GHz}$ to $13 \mathrm{GHz}$ " (10 GHz Bandwidth slot). Modification of paper [7] done in [8], where a compact planar ultra wideband (UWB) antenna is designed for wireless universal serial bus (USB) dongle application. Cutting 7 notches and embedding types of slots into a rectangular patch, multiple resonances with effective bandwidth enhancement is achieved. This prototype antenna is constructed and measured to show an ultra wide operating band with $10-\mathrm{dB}$ return-less bandwidth of about $10.42 \mathrm{GHz}$ ranging from " $2.86 \mathrm{GHz}$ to $13.38 \mathrm{GHz}$," highest bandwidth modification done in [9]. The gain enhancement technique is displayed, which loosely configured grooved ground plan able to significantly enhance the gain of a standard patch antenna with a flat, electrically large ground plan. Simulation and measurement results show the enhancement of the gain up to $10.2 \mathrm{dBi}$ at $10.45 \mathrm{GHz}$ and the proposed antenna is designed to achieve usable bandwidth $12.2 \mathrm{GHz}$ from " $5.8 \mathrm{GHz}$ to $18.15 \mathrm{GHz}$." The proposed design of antenna in this paper is modification of [6-9] to achieve more $-10 \mathrm{~dB}$ impedance bandwidth slot and directivity.

\section{Proposed Geometry Design}

The Proposed Geometry consists of

(i) $\Delta=3$ mil air gap between top and bottom layer,

(ii) geometry which consists of glass epoxy PCB and air gap (FR-4 - air-FR-4) material,

(iii) total height of geometry which is $3.07 \mathrm{~mm}$ (from a ground plan to top layer),

(iv) middle layer driven element which has patch dimension $L \times W=10.44 \mathrm{~mm} \times 11.32 \mathrm{~mm}(0.1808 \lambda \mathrm{mm} \times$ $0.1962 \lambda \mathrm{mm})$,

(v) top parasitic patches which have dimension of $L_{1} \times$ $W_{1}=2.54 \mathrm{~mm} \times 3.81 \mathrm{~mm}(0.044 \lambda \mathrm{mm} \times 0.066 \lambda \mathrm{mm})$ used as director,

(vi) the dimensions of ground plan which is $28.87 \mathrm{~mm} \times$ $29.76 \mathrm{~mm}(0.05 \lambda \mathrm{mm} \times 0.05154 \lambda \mathrm{mm})$ used as a reflector.

The geometry consists of two U-type patches on the left side of the top layer shown in Figure 2. The proposed geometry is simulated using IE3D simulator.

\section{Mutual Coupling Approach for Designing of Proposed Antenna}

The proposed antenna is design to reduce the total mutual inductance of geometry, in geometry U-type patch directors is configured in out-of-phase mutual coupling through vertical arms of U-patch is shown in Figure 3. Two sections of U-patch carrying currents in the same direction have positive mutual inductance here as the inductance is negative for a current flowing in opposite directions is shown in Figure 4. The lengthening of the effective patch's surface current paths is due to the additional downward paths in the added rims, which is different from that of the meandered designs; a relatively very small perturbation on the excited surface current distribution in the radiating patch is expected. This implies that it is possible for the radiation characteristics of this compact design to be as good as those of a corresponding conventional patch antenna with a planar radiating patch. Adjacent resonant modes with similar radiation characteristics can be excited at frequencies close to each other, resulting in a wide bandwidth microstrip antenna. Furthermore by properly adjusting the parameters of slots, both of the adjacent resonant modes could achieve good impedance matching, which makes the antenna broadband and compact:

$$
\begin{aligned}
& L_{\text {Total }}=\Sigma L+\Sigma M_{+}-\Sigma M_{-}, \\
& \Sigma M_{-}=2 \Sigma M_{13}+\Sigma L_{m g}+2 \Sigma M_{34}+2 \Sigma M_{46}+2 \Sigma M_{16} \text {, } \\
& M_{13}=2 \times 10^{-4} l_{e}\left[\operatorname{In}\left\{\frac{l_{e}}{d}+\sqrt{1+\left(\frac{l_{e}}{d}\right)^{2}}\right\}\right. \\
& \left.+\frac{d}{2 l}-\sqrt{1+\left(\frac{d}{l_{e}}\right)^{2}}+\frac{d}{l_{e}}\right] \\
& M_{34}=2 \times 10^{-4} l_{e 1}\left[\operatorname{In}\left\{\frac{l_{e 1}}{d_{34}}+\sqrt{1+\left(\frac{l_{e 1}}{d_{34}}\right)^{2}}\right\}\right. \\
& \left.+\frac{d_{34}}{2 l_{e 1}}-\sqrt{1+\left(\frac{d_{34}}{l_{e 1}}\right)^{2}}+\frac{d_{34}}{l_{e 1}}\right], \\
& M_{16}=2 \times 10^{-4} l_{e 2}\left[\operatorname{In}\left\{\frac{l_{e 2}}{d_{16}}+\sqrt{1+\left(\frac{l_{e 2}}{d_{16}}\right)^{2}}\right\}\right. \\
& \left.+\frac{d_{16}}{2 l_{e 2}}-\sqrt{1+\left(\frac{d_{34}}{l_{e 2}}\right)^{2}}+\frac{d_{16}}{l_{e 2}}\right],
\end{aligned}
$$

where $l_{e}$ is the effective length of the arms between 1 and 3 , which calculated the mutual inductance $M_{13}$. Dimensions of $l_{e}$ and $d$ are in microns and $M_{13}$ is in nanohenries. As an approximation, $l_{e}$ can be considered an average length for three sections $l_{e}=l_{1}+l_{2}+l_{3}, l_{e 1}$ is an effective length of the sections 3 and 4 , and $l_{e 2}$ is the effective length of sections 1 and $6 . d_{16}$ and $d_{34}$ are distance between 1 and 6, 3 and 4, respectively. $M_{16}$ and $M_{34}$ are mutual inductance between 1 and 6,3 and 4 , respectively.

So total inductance of $\mathrm{U}$-patch is

$$
L=L_{1}+L_{2}+L_{3}+X_{P} .
$$

The free-space inductance $L$ (in nanohenries) of a width of $\mathrm{U}$-patch is $d$ and $l$ length, (in microns) given by [10, 11]. 


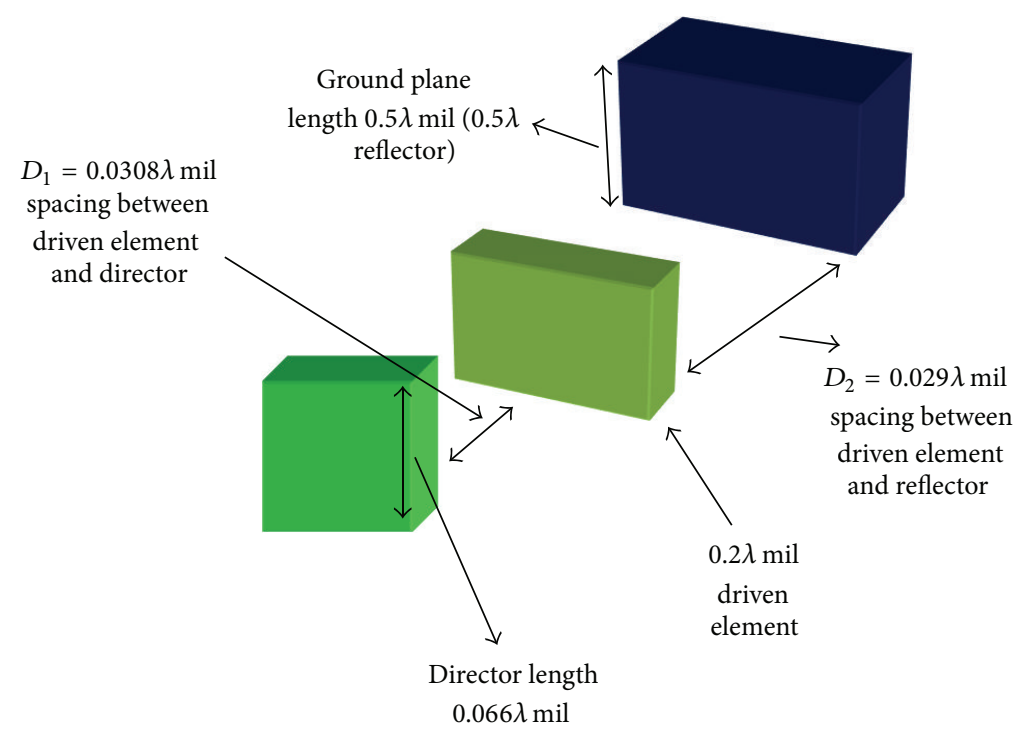

Figure 1: Proposed model.

For $l \ll d$

$l=$ length of U-patch,

$d=$ width of $\mathrm{U}$-patch:

$$
\begin{gathered}
L_{1}=L_{3}=2 \times 10^{-4} l\left[\operatorname{In}\left\{\frac{2 l}{d}+\sqrt{1+\left(\frac{2 l}{d}\right)^{2}}\right\}\right. \\
+\frac{d}{2 l}-\sqrt{\left.1+\left(\frac{d}{2 l}\right)^{2}+C\right],} \\
\begin{array}{r}
L_{2}=2 \times 10^{-4} l_{2}\left[\operatorname{In}\left\{\frac{2 l_{2}}{d}+\sqrt{1+\left(\frac{2 l_{2}}{d}\right)^{2}}\right\}\right. \\
\left.+\frac{d}{2 l_{2}}-\sqrt{1+\left(\frac{d}{2 l_{2}}\right)^{2}}+C\right],
\end{array}
\end{gathered}
$$

where $l_{1}=l_{2}=l$

$$
\begin{aligned}
& C=0.25 \tanh \left(\frac{4 \delta}{d}\right), \\
& \delta=\frac{1}{\sqrt{\pi \sigma f \mu}} .
\end{aligned}
$$

The inductor $X_{P}$ produced by the probe is given by

$$
X_{P}=\frac{\eta}{\pi} \tan \left(0.5 k_{o} h\right) \operatorname{In}\left(\frac{2.25}{k_{o} d}\right) .
$$

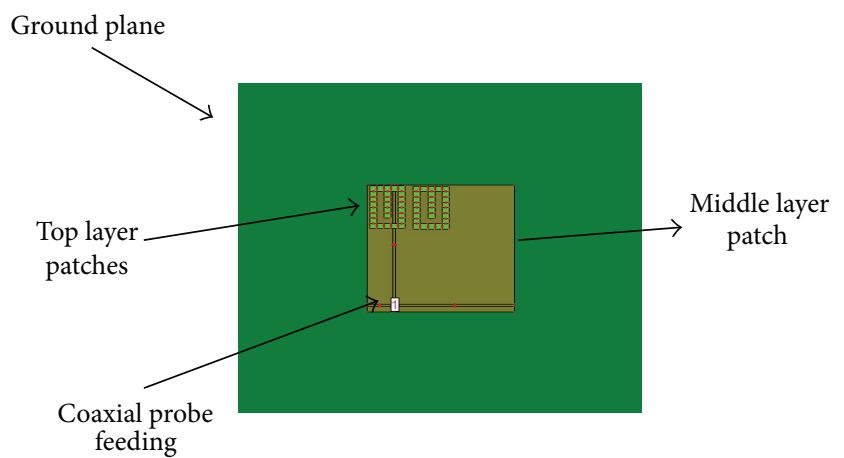

FIGURE 2: Optimization model for geometry.

$l \gg d$ where $\sigma$ is the conductivity of the wire material. For gold wires, $\delta=2.486 f-0.5$, where frequency $f$ is expressed in gigahertz. When $\delta / d$ are small, $C=\delta / d$.

When $1 \gg d,(4),(5)$ reduces to

$$
\begin{aligned}
L_{1} & =L_{3}=2 \times 10^{-4} l\left(\operatorname{In} \frac{4 l}{d}+0.5 \frac{d}{l}-1+C\right), \\
L_{2} & =2 \times 10^{-4} l_{2}\left(\operatorname{In} \frac{4 l_{2}}{d}+0.5 \frac{d}{l_{2}}-1+C\right), \\
L & =L_{1}+L_{2}+L_{3}+X_{P} .
\end{aligned}
$$

3.1. Ground Plan Effect. The effect of the ground plan on the inductance value of an antenna has also been considered [12]. If the radiating patch is at a distance $h$ above the ground plan as shown in Figure 1, it sees its image at $2 \mathrm{~h}$ from it. The U-Slot patches and its image consists mutual inductance $L_{m g}$. Because the image of antenna carries a current opposite to the current flow in the patch, the mutual inductance of 


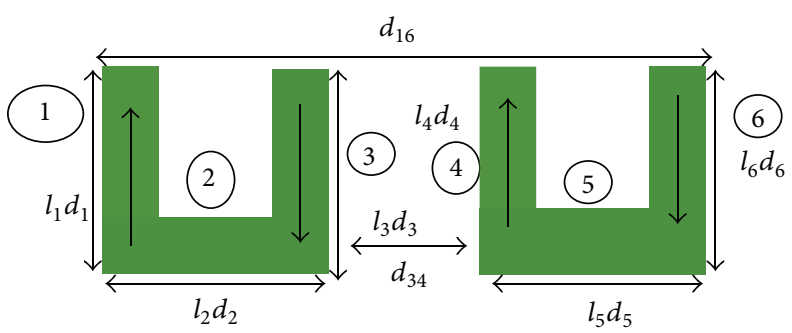

FIGURE 3: U-patch model for mutual coupling approach.

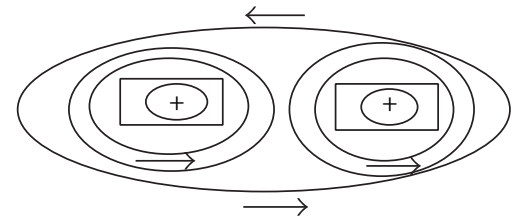

(a)

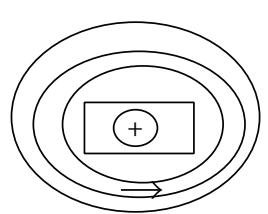

(b)

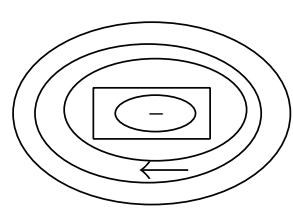

Figure 4: (a) Positive mutual coupling and (b) out-of-phase coupling.

the antenna $L_{m g}$ is calculated from (6) by mutual coupling approach

$$
\begin{aligned}
L_{m g}=2 \times 10^{-4} l[ & \text { In }\left\{\frac{l}{2 h}+\sqrt{1+\left(\frac{l}{2 h}\right)^{2}}\right\} \\
& +\sqrt{1+\left(\frac{l}{2 h}\right)^{2}}+\frac{2 h}{l} \\
& \left.-\sqrt{1+\left(\frac{2 h}{l}\right)^{2}}+C\right] .
\end{aligned}
$$

\section{Optimization Using Ground Plan}

In this optimization section, proposed antenna is optimized using only change in dimension of ground plan. The dimension of ground plan severely has an effect on reflected signal; according to (10), $L_{m g}$ is mutual inductance of ground plan and depends on the dimensions length of ground plan, width of ground plan, total height of antenna, loss tangent of dielectric material, and conductivity of ground plan. When the dimensions of ground plan increase the mutual inductance of the ground plan $\left(L_{m g}\right)$ also increases so that overall out-of-phase inductance increases as per (2) and total dominate inductance of proposed design is reduced and achieved reduction in reflected signal; this optimization approach provides impedance matching over a wide band of frequency and this approach is more feasible and easy. When the dimension of ground plan changes from $11.43 \times 13.97 \mathrm{~mm}^{2}$ to $28.87 \times 29.76 \mathrm{~mm}^{2}$, simultaneously the useful $-10 \mathrm{~dB}$ impedance matching bandwidth slot improves from $8 \mathrm{GHz}$ to $12.2 \mathrm{GHz}$. After $28.87 \times 29.76 \mathrm{~mm}^{2}$ ground dimension, the increment in dimension of ground plan is not feasible because size of antenna is not compatible over a useful bandwidth slot and therefore optimization is done up to 28.87 $\times 29.76 \mathrm{~mm}^{2}$ only.
4.1. Optimization Using Ground Plan Dimensions $11.43 \times$ $13.97 \mathrm{~mm}^{2}$. In this optimization section, the dimensions of ground plan are changed; the dimension of ground plan is $11.43 \times 13.97 \mathrm{~mm}^{2}$ and achieved $-10 \mathrm{~dB}$ impedance bandwidth $8 \mathrm{GHz}$ is shown in Figure 5(a).

4.2. Optimization Using Ground Plan of Dimensions $12.7 \times$ $12.7 \mathrm{~mm}^{2}$. In this optimization section, the dimension of ground plan is $12.7 \times 12.7 \mathrm{~mm}^{2}$ and obtained $-10 \mathrm{~dB}$ impedance bandwidth $8.9 \mathrm{GHz}$ is shown in Figure 5(b).

4.3. Optimization Using Ground Plan of Dimensions Is $12.7 \times$ $13.97 \mathrm{~mm}^{2}$. In this optimization section, the dimension of ground plan is $12.7 \times 13.97 \mathrm{~mm}^{2}$ and obtained $-10 \mathrm{~dB}$ impedance bandwidth $9 \mathrm{GHz}$ is shown in Figure 5(c).

4.4. Optimization Using Ground Plan of Dimensions Is $28.87 \times$ $29.76 \mathrm{~mm}^{2}$. From the validation of proposed geometry in IE3D simulator, obtained $-10 \mathrm{~dB}$ impedance bandwidth is 12.2 GHz and return losses of $-20 \mathrm{~dB}$ as shown in Figure 5(d). Simulation results obtained for 5.8 to $18 \mathrm{GHz}$ frequency slots and at $12 \mathrm{GHz}$ achieved $-20 \mathrm{~dB}$ return loss.

The results of all optimization section using ground plan are shown in Table 2.

\section{Results and Discussion}

The proposed structure consists of one reflector of dimension $0.5 \lambda \mathrm{mm} \times 0.5154 \lambda \mathrm{mm}$. The dimensions of reflector give 180 deg phase shift so that all the reflected waves will be reflected from the reflector and move towards the director and achieved elimination of reflected waves over wide range of frequency. The dimension of the driven element is $0.1808 \lambda \mathrm{mm} \times 0.1962 \lambda \mathrm{mm}$ giving $70 \mathrm{deg}$ phase shift for forward wave with the intention that wave is coupled more towards the director. In antenna theory gain, bandwidth does not increase simultaneously if gain of the antenna is more than bandwidth of antenna which is less but in our 


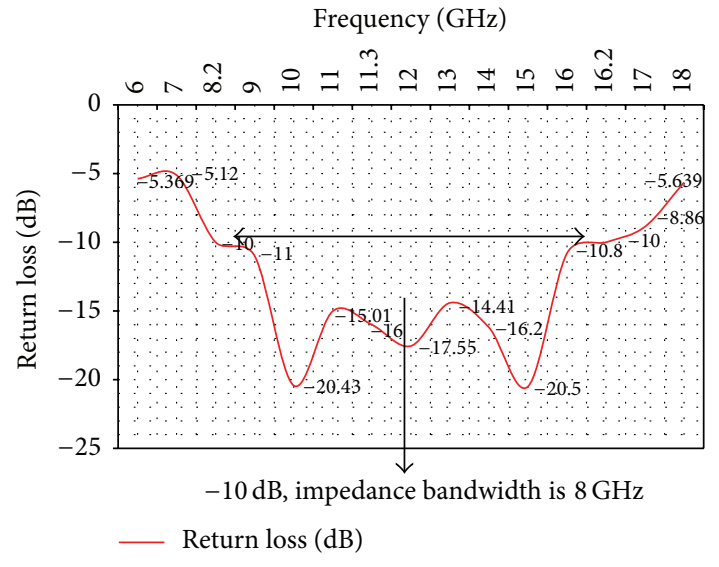

(a)

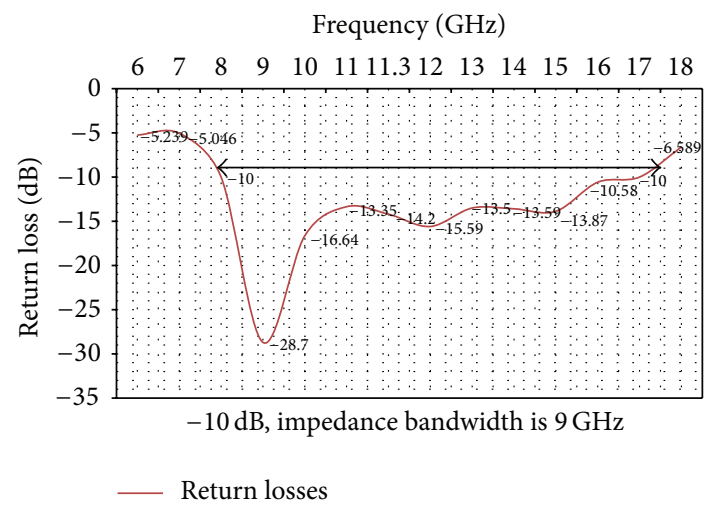

(c)

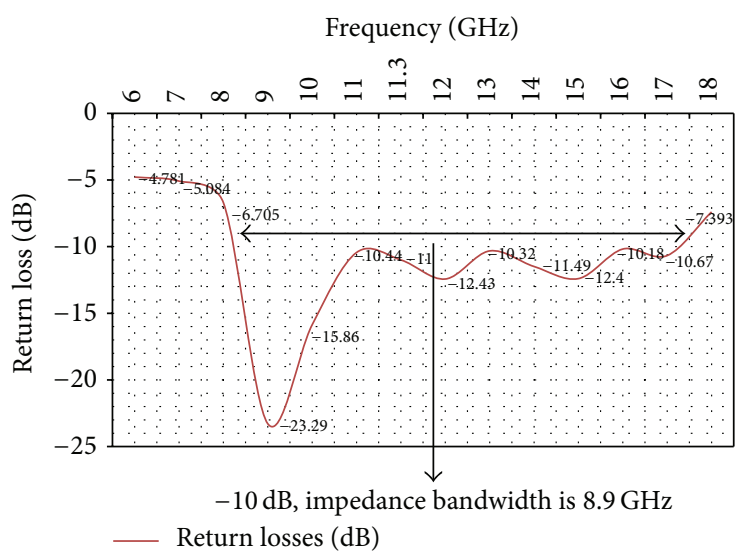

(b)

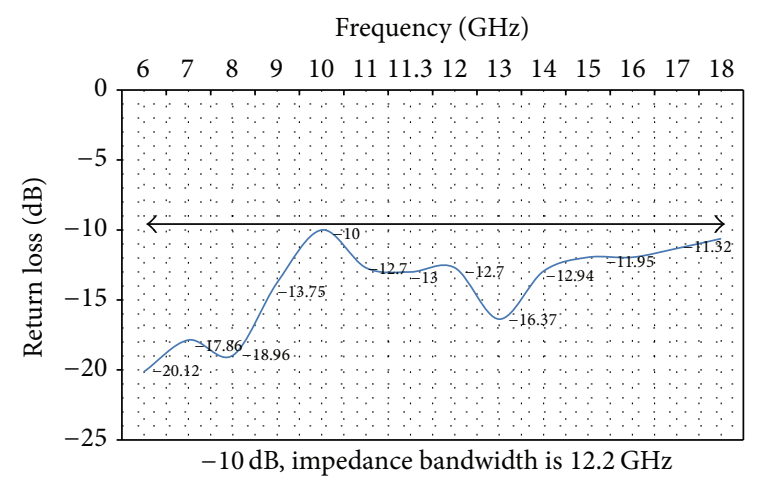

(d)

FIGURE 5: (a) Return losses versus frequency for dimension of ground plan $11.43 \times 13.97 \mathrm{~mm}^{2}$. (b) Return losses versus frequency for dimension of ground plan $12.7 \times 12.7 \mathrm{~mm}^{2}$. (c) Return losses versus frequency for dimension of ground plan $12.7 \times 13.97 \mathrm{~mm}^{2}$. (d) Return losses versus frequency.

design required optimal gain over a broad bandwidth therefore considered an appropriate dimension, $0.1808 \lambda \mathrm{mm} \times$ $0.1962 \lambda \mathrm{mm}$ dimensions for driving element; the spacing between elements is $D_{1}=0.038 \lambda \mathrm{mm}$ and $D_{2}=0.02 \lambda \mathrm{mm}$; the spacing between elements gives $10 \mathrm{deg}$ phase shift so that the signal cannot losses between elements and maximum signal coupled to director. The dimension of U-type novel director is $0.044 \lambda$ mil $\times 0.066 \lambda$ mil; director exists in $13 \mathrm{deg}$ phase shift and consequently all forward wave has received and again has been amplified by the director so that it achieved optimum gain from $5.8 \mathrm{GHz}$ to $18 \mathrm{GHz}$.

The wide band operation is obtained from proposed structures. The $0.5 \lambda \mathrm{mm} \times 0.5154 \lambda \mathrm{mm}$ ground plan is inductive in nature in order to provided impedance matching for lower frequency. The middle layer patch $0.1808 \lambda \mathrm{mm} \times$ $0.1962 \lambda \mathrm{mm}$ is resistive in nature and provided impedance matching for middle frequency. The top layer patch $0.044 \lambda \mathrm{mm} \times 0.066 \lambda \mathrm{mm}$, is capacitive in nature and provided impedance matching for high frequency. Appropriate U-type patches and appropriate dimensions of ground plan reduced total inductance of geometry by increasing out-ofphase inductance of geometry and providing impedance matching over broad bandwidth, the range of broad band decided by the length, width of U-type patch, spacing between $U$ Type patches, and dimension of ground plan.

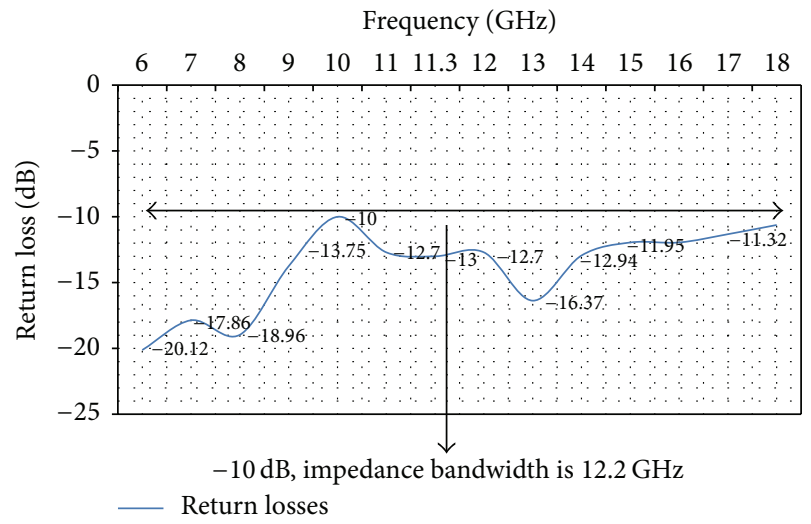

FIGURE 6: Return losses versus frequency.

5.1. Return Losses versus Frequency. From the validation of proposed geometry in IE3D simulator, $-10 \mathrm{~dB}$ impedance bandwidth is $12.2 \mathrm{GHz}$ as is shown in Figure 6 and return losses of $-20 \mathrm{~dB}$. Simulation results obtained for 5.8 to $18 \mathrm{GHz}$ frequency slots.

5.2. Gain versus Frequency. The simulation result in Figure 7 concluded that out-of-phase coupling severely reduced 


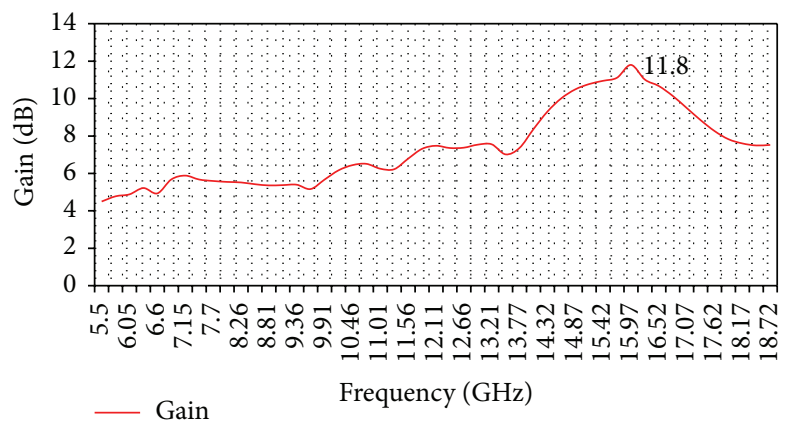

FIgURE 7: Gain versus frequency.

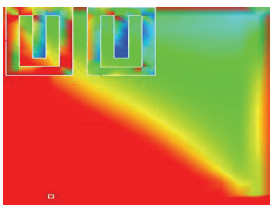

$f=5.5 \mathrm{GHz}$

(a)

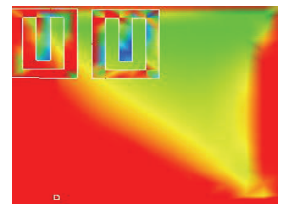

$f=6.32 \mathrm{GHz}$

(b)

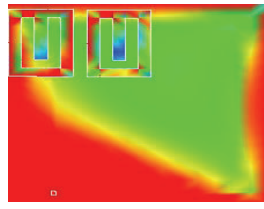

$f=7.15 \mathrm{GHz}$

(c)

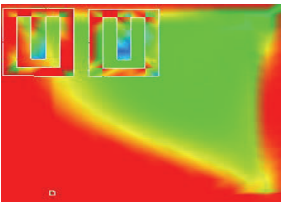

$f=7.979 \mathrm{GHz}$

(d)

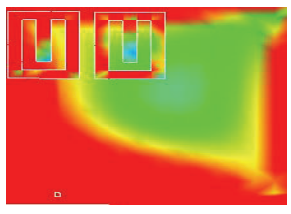

$f=9.08 \mathrm{GHz}$

(e)

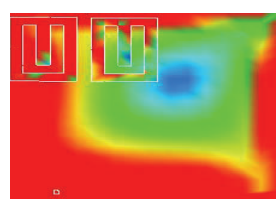

$f=10.18 \mathrm{GHz}$

(f)

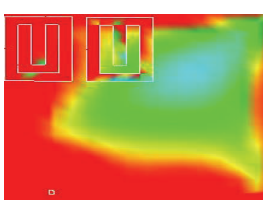

$f=11 \mathrm{GHz}$

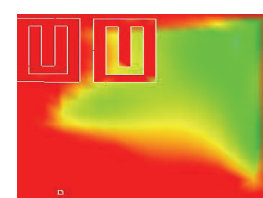

$f=12 \mathrm{GHz}$

(g)

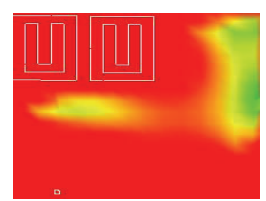

$f=13 \mathrm{GHz}$

(i)

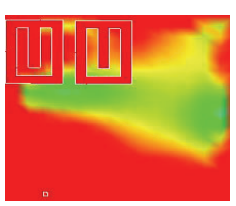

$f=14 \mathrm{GHz}$

(j)

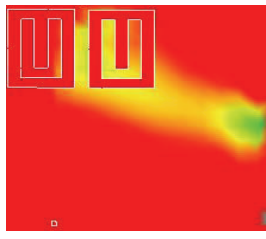

$f=15 \mathrm{GHz}$

(k)

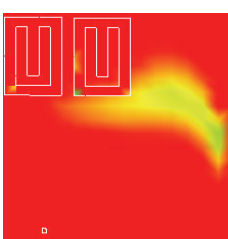

$f=16 \mathrm{GHz}$

(1)

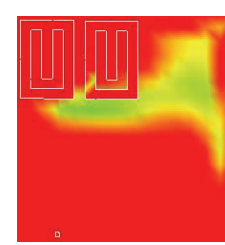

$f=17 \mathrm{GHz}$

(m)

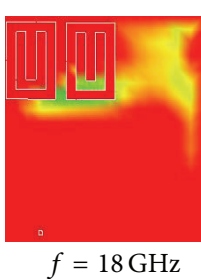

(n)

Figure 8: Current density of geometry at different frequency.

the inductance of design and improved gain, achieved gain $4 \mathrm{dBi}$ to $11.8 \mathrm{dBi}$; the maximum value of gain $11.8 \mathrm{dBi}$ is at $15.97 \mathrm{GHz}$.

5.3. Current Density at Different Frequency for Geometry-I. Using IE3D simulator observed current density, the current density analysis is shown in Figure 8 and found higher current density towards a higher range of frequency and obtained higher radiating and antenna efficiency towards the higher edge of frequency.

All comparison results for geometry are shown in Table 1 which shows comparable results in terms of VSWR, return losses ( $111 \leq-10 \mathrm{~dB})$, and impedance bandwidth, analyzed geometry, and got impedance bandwidth VSWR $\leq 2$ and $-10 \mathrm{~dB}$ and impedance bandwidth up to $12.2 \mathrm{GHz}$ (Table 3). The gain of geometry in Figure 8 varies from $5 \mathrm{dBi}$ to $11.8 \mathrm{dBi}$.
The proposed geometry is appropriate for C-band, X-band and $\mathrm{Ku}$-band application. Fabricated and validation is done for the proposed geometry.

\subsection{Radiation Pattern}

5.4.1. Elevation Radiation Pattern at $f=18.17 \mathrm{GHz}$, phi $(\phi)=$ $70 \mathrm{deg}$. See Figure 9(a).

5.4.2. Elevation Radiation Pattern at $f=10.4592 \mathrm{GHz}$, phi $(\phi)=50$ deg. See Figure 9(b).

Current distribution simulation shows what areas of the antenna are excited (Figure 8). It is interesting to note that the current distribution does not follow any regular pattern as in the case of regular shapes. At $10.45 \mathrm{GHz}, 12.11 \mathrm{GHz}$, 15.97 GHz, $16.24 \mathrm{GHz}, 17.07 \mathrm{GHz}$, and $18.17 \mathrm{GHz}$ the gain 


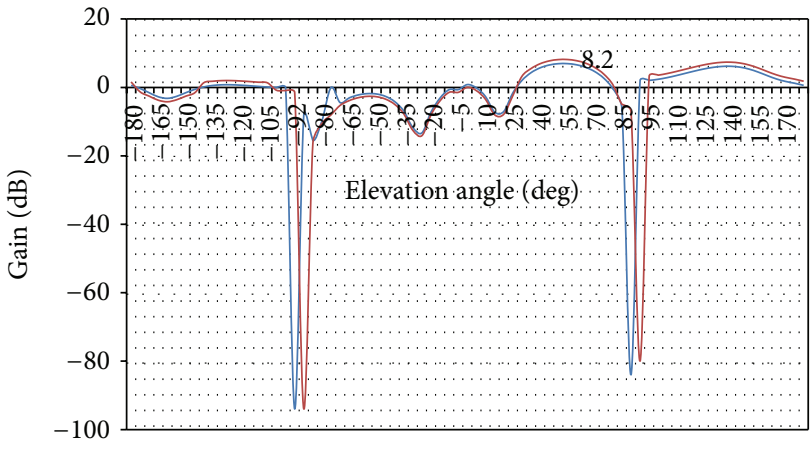

Measurement result _ Simulation result

(a)

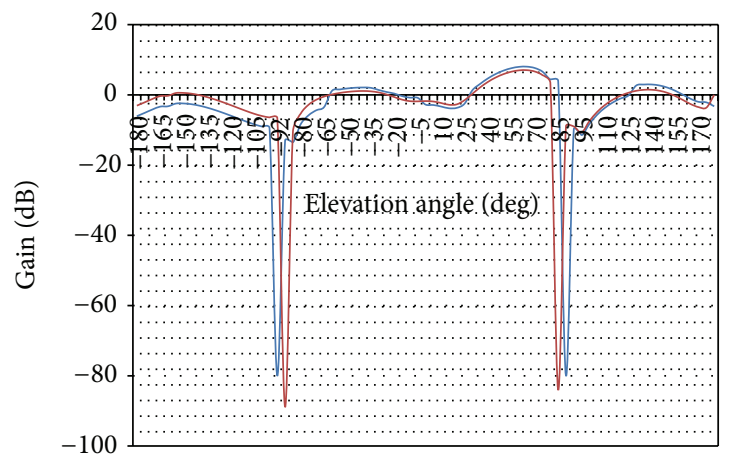

- Simulation result

_ Measurement result

(c)

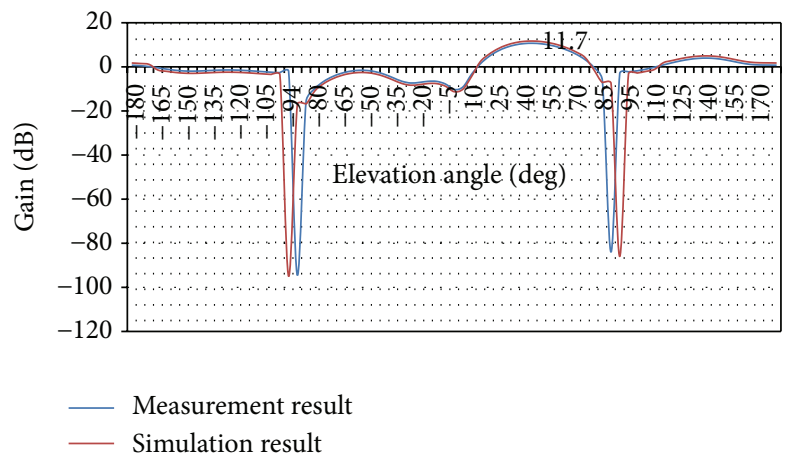

(e)

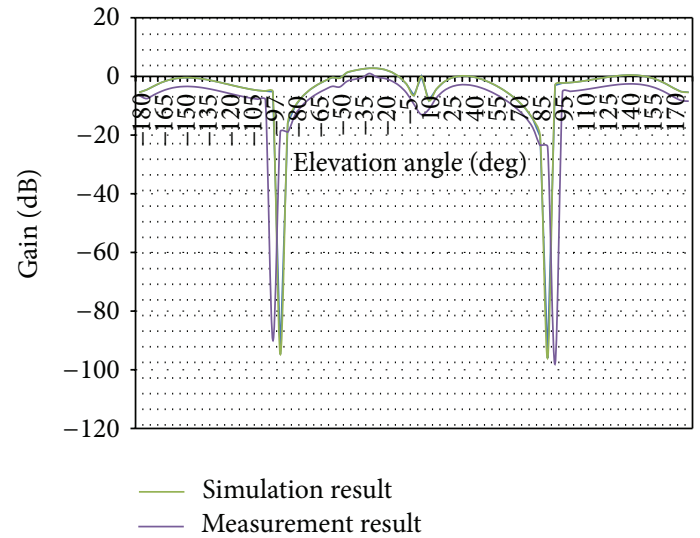

(b)

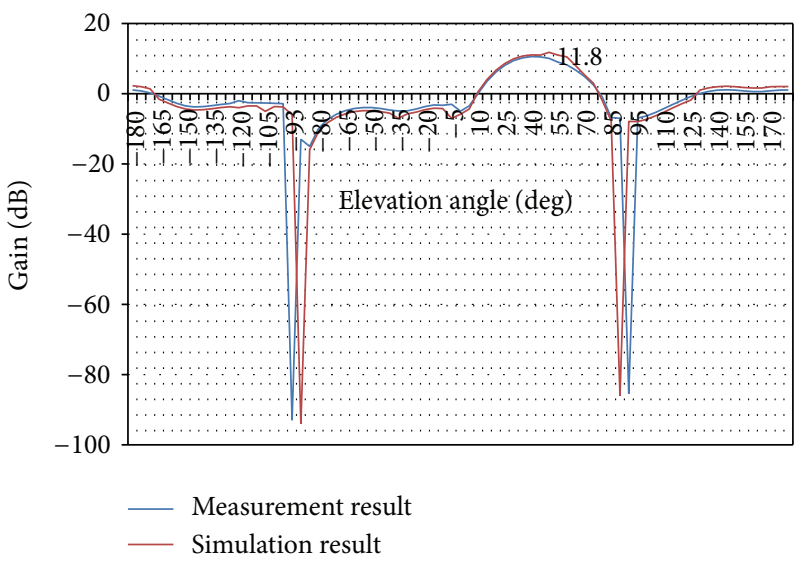

(d)

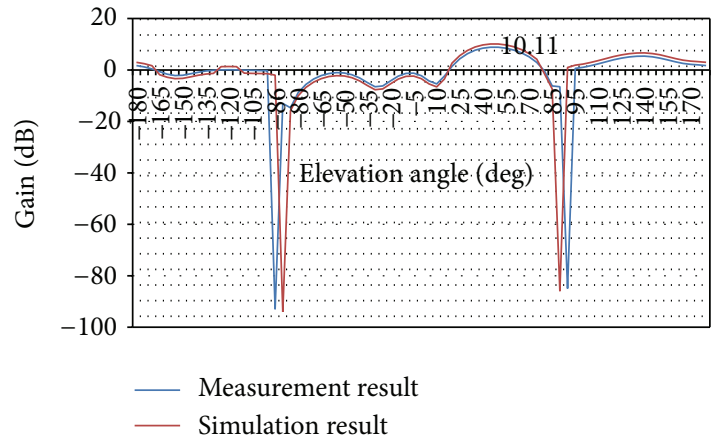

(f)

Figure 9: (a) Elevation radiation pattern at $f=18.17 \mathrm{GHz}$, phi $(\phi)=70 \mathrm{deg}$. (b) Elevation radiation pattern at $f=10.4592 \mathrm{GHz}$, phi $(\phi)=$ $50 \mathrm{deg}$. (c) Elevation radiation pattern at $f=12.1122 \mathrm{GHz}$, phi $(\phi)=50 \mathrm{deg}$. (d) Elevation radiation pattern at $f=15.97 \mathrm{GHz}, \operatorname{phi}(\phi)=$ $50 \mathrm{deg}$. (e) Elevation radiation pattern at $f=16.2449 \mathrm{GHz}, \operatorname{phi}(\phi)=60 \mathrm{deg}$. (f) Elevation radiation pattern at $f=17.0714 \mathrm{GHz}, \operatorname{phi}(\phi)=$ $70 \mathrm{deg}$.

TABle 1: Dimension of proposed design.

\begin{tabular}{lccc}
\hline & \multicolumn{3}{c}{ Dimension of top layer } \\
Length of U-slot $L_{1}$ & $2.54 \mathrm{~mm}$ & Width of U-slot $W_{1}$ & $3.81 \mathrm{~mm}$ \\
\hline Length of middle patch $L$ & $10.4394 \mathrm{~mm}$ & Dimension of middle layer & Width of middle patch $W$ \\
\hline & \multicolumn{2}{c}{ Dimension of ground plan } & $11.33 \mathrm{~mm}$ \\
\hline Length of ground plan $L_{g}$ & $28.87 \mathrm{~mm}$ & Width of ground plan $W_{g}$ & $29.76 \mathrm{~mm}$ \\
\hline
\end{tabular}




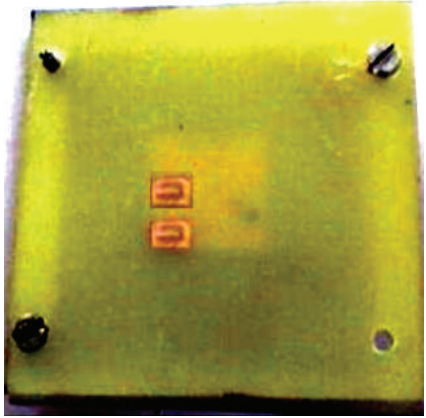

(a)

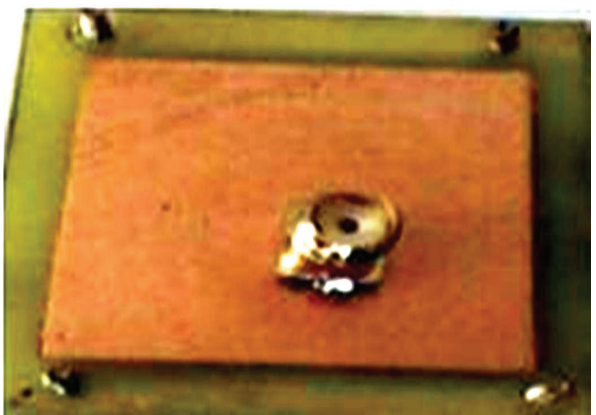

(b)

Figure 10: (a) Front view of fabricated antenna. (b) Bottom view of fabricated antenna.

TABLE 2: Optimization of bandwidth using different ground plan dimensions.

\begin{tabular}{lcccc}
\hline Ground plan dimension & $11.43 \times 13.97 \mathrm{~mm}^{2}$ & $12.7 \times 12.7 \mathrm{~mm}^{2}$ & $12.7 \times 13.97 \mathrm{~mm}^{2}$ & $28.87 \times 29.76 \mathrm{~mm}^{2}$ \\
\hline Useful bandwidth & $8 \mathrm{GHz}$ & $8.9 \mathrm{GHz}$ & $9 \mathrm{GHz}$ & $12.2 \mathrm{GHz}$ \\
\hline
\end{tabular}

TABLE 3: Validation of antenna parameters of different geometry with reference paper.

\begin{tabular}{lccc}
\hline Antenna parameters & Proposed work & Reference [6] & Reference [7] \\
\hline$-10 \mathrm{~dB}$, Impedance bandwidth & $12.2 \mathrm{GHz}$ & $10.42 \mathrm{GHz}(2.86 \mathrm{GHz}$ to $13.38 \mathrm{GHz})$ & $10 \mathrm{GHz}(3 \mathrm{GHz}$ to $13 \mathrm{GHz})$ \\
VSWR $\leq$ 2, Impedance bandwidth & $12.2 \mathrm{GHz}$ & $10.42 \mathrm{GHz}(2.86 \mathrm{GHz}$ to $13.38 \mathrm{GHz})$ & $10 \mathrm{GHz}(3 \mathrm{GHz}$ to $13 \mathrm{GHz})$ \\
\hline
\end{tabular}

Proposed geometry reported impedance bandwidth greater than $12 \mathrm{GHz}$.

values are $4 \mathrm{dBi}, 8 \mathrm{dBi}, 11.8 \mathrm{dBi}, 11.7 \mathrm{dBi}, 10.11 \mathrm{dBi}$, and $8.2 \mathrm{dBi}$, respectively. In conclusion, it can be seen from the simulation results that the antenna performs well at the operating frequency $5.8 \mathrm{GHz}$ to $18 \mathrm{GHz}$. There is also some deviation from the theoretically expected operating frequency; the main reason for this is the discretization applied during simulation.

5.4.3. Elevation Radiation Pattern at $f=12.1122 \mathrm{GHz}$, phi $(\phi)=50$ deg. See Figure 9(c).

5.4.4. Elevation Radiation Pattern at $f=15.97 \mathrm{GHz}$, phi $(\phi)=$ $50 \mathrm{deg}$. See Figure 9(d).

5.4.5. Elevation Radiation Pattern at $f=16.2449 \mathrm{GHz}$, phi $(\phi)=60$ deg. See Figure 9(e).

5.4.6. Elevation Radiation Pattern at $f=17.0714 \mathrm{GHz}$, $\operatorname{phi}(\phi)=70 \mathrm{deg}$. See Figure 9(f).

\section{Fabrication of Proposed Structure}

The fabricate antenna used FR-4 and air, the layout of the antenna is designed in AUTO CAD software, its etching is done using ferric-chloride acid. For feeding SMA connector is used (Figure 10).

\section{Hardware Validation of Fabricated Antenna}

There are some deviation 0.108 values from the theoretically expected; the main reason for this is the discretization applied

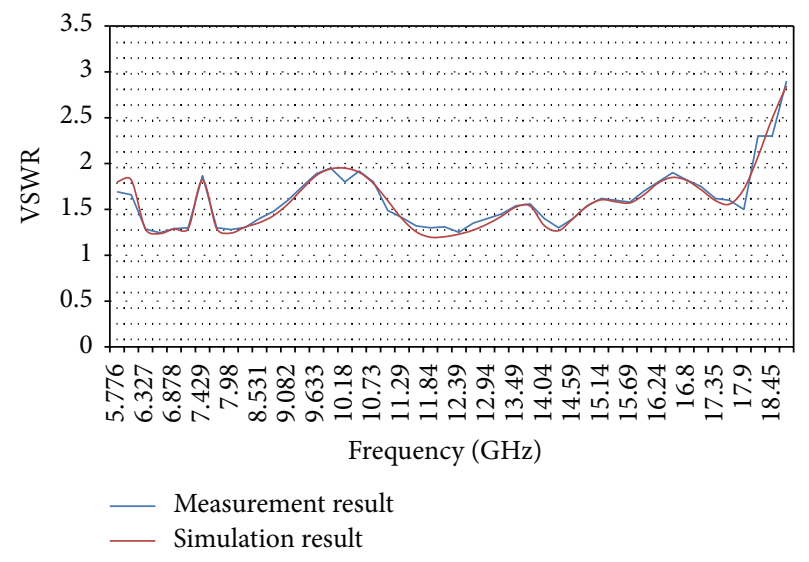

FIGURE 11: VSWR measurement of fabricated antenna.

during simulation. Figure 11 shows hardware validation of fabricated antenna.

\section{Conclusion}

In this paper, the out-of-phase inductance coupling approach is used for designing of proposed geometry; the out-ofphase inductance consists of two U-type patches and ground plan. This is justified in mutual coupling approach; after the analysis of the results of the proposed antenna, it is concluded that the total inductance is optimized, reflection is reduced and enhanced surface current over wide bandwidth 
(12.2 GHz); achieved impedance bandwidth S11 $(\leq-10 \mathrm{~dB}$ impedance bandwidth) from $5.8 \mathrm{GHz}$ to $18 \mathrm{GHz}$ is $102 \%$, VSWR $\leq 2$ over $12.2 \mathrm{GHz}$ bandwidth slot. Utilized impedance bandwidth, $38 \%$ of X-band, $19 \%$ of C-band and $45 \%$ of $\mathrm{Ku}$-band, achieved gain " $4 \mathrm{dBi}$ to $11.8 \mathrm{dBi}$ " over $12.2 \mathrm{GHz}$ impedance bandwidth slot. This proposed antenna geometry can be used for X-band, Ku-band, and C-band application. The hardware validation and simulation results are matched to this design. In this research we observed that ground dimension $0.5 \lambda \mathrm{mm} \times 0.5154 \lambda \mathrm{mm}$ has improved the efficiency and useful bandwidth of antenna.

\section{Conflict of Interests}

The authors declare that there is no conflict of interests regarding the publication of this paper.

\section{References}

[1] J. Anguera, E. Martínez, C. Puente, C. Borja, and J. Soler, "Broad-band dual-frequency microstrip patch antenna with modified Sierpinski fractal geometry," IEEE Transactions on Antennas and Propagation, vol. 52, no. 1, pp. 66-73, 2004.

[2] J. Anguera, E. Martínez-Ortigosa, C. Puente, C. Borja, and J. Soler, "Broadband triple-frequency microstrip patch radiator combining a dual-band modified Sierpinski fractal and a monoband antenna," IEEE Transactions on Antennas and Propagation, vol. 54, no. 11, pp. 3367-3373, 2006.

[3] F.-J. Huang, T.-C. Yo, C.-M. Lee, and C.-H. Luo, "Design of circular polarization antenna with harmonic suppression for rectenna application," IEEE Antennas and Wireless Propagation Letters, vol. 11, pp. 592-595, 2012.

[4] S.-S. Zhong, Z. Sun, L.-B. Kong, C. Gao, W. Wang, and M.P. Jin, "Tri-band dual-polarization shared-aperture microstrip array for SAR applications," IEEE Transactions on Antennas and Propagation, vol. 60, no. 9, pp. 4157-4165, 2012.

[5] Y. Sung, "Bandwidth enhancement of a microstrip line-fed printed wide-slot antenna with a parasitic center patch," IEEE Transactions on Antennas and Propagation, vol. 60, no. 4, pp. 1712-1716, 2012.

[6] C.-M. Wu, Y.-L. Chen, and W.-C. Liu, "A compact ultrawideband slotted patch antenna for wireless USB dongle application," IEEE Antennas and Wireless Propagation Letters, vol. 11, pp. 596-599, 2012.

[7] T. Li, H.-Q. Zhai, G.-H. Li, and C.-H. Liang, "Design of compact UWB band-notched antenna by means of electromagneticbandgap structures," Electronics Letters, vol. 48, no. 11, pp. 608609, 2012.

[8] M. Bod, H. R. Hassani, and M. M. S. Taheri, "Compact UWB printed slot antenna with extra bluetooth, GSM, and GPS bands," IEEE Antennas and Wireless Propagation Letters, vol. 11, pp. 531-534, 2012.

[9] B. Lv, X. Wang, C. Zheng, J. Huangfu, C. Li, and L. Ran, "Radiation enhancement for standard patch antennas using a loosely grooved ground plane " IEEE Antennas and Wireless Propagation Letters, vol. 11, pp. 604-607, 2012.

[10] G. Kumar and K. C. Gupta, "Non radiating edges and four edges gap-coupled multiple resonator, broadband microstrip antennas," IEEE Transactions on Antennas and Propagation, vol. AP-33, no. 2, pp. 173-178, 1985.
[11] K. Siakavara and T. Ganatsos, "Modification of the radiation patterns of higher order modes of triangular printed antennas by EBG ground planes," IEEE Antennas and Wireless Propagation Letters, vol. 8, pp. 124-128, 2009.

[12] F. E. Terman, Radio Engineer Handbook, McGraw-Hill, New York, NY, USA, 1943. 

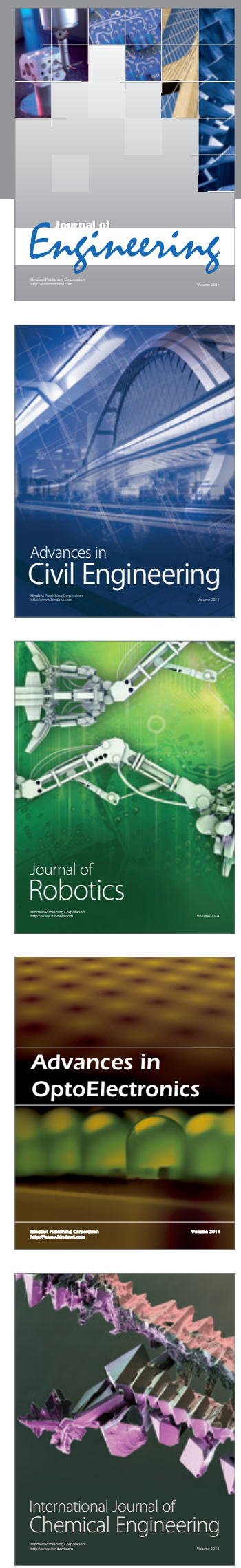

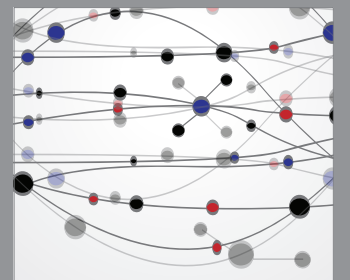

The Scientific World Journal
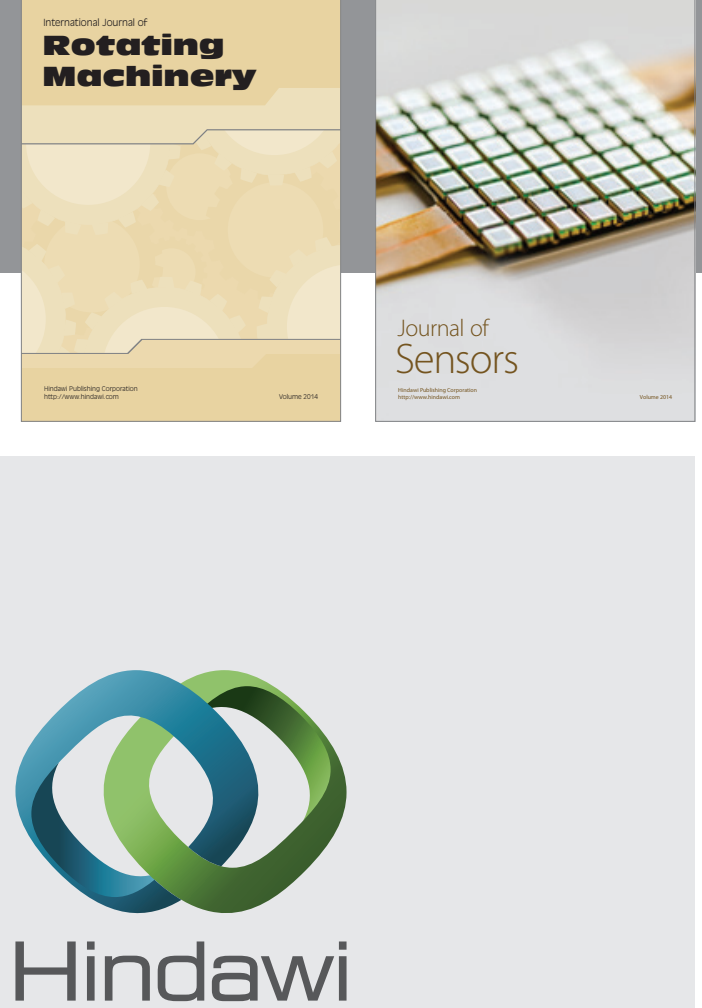

Submit your manuscripts at http://www.hindawi.com
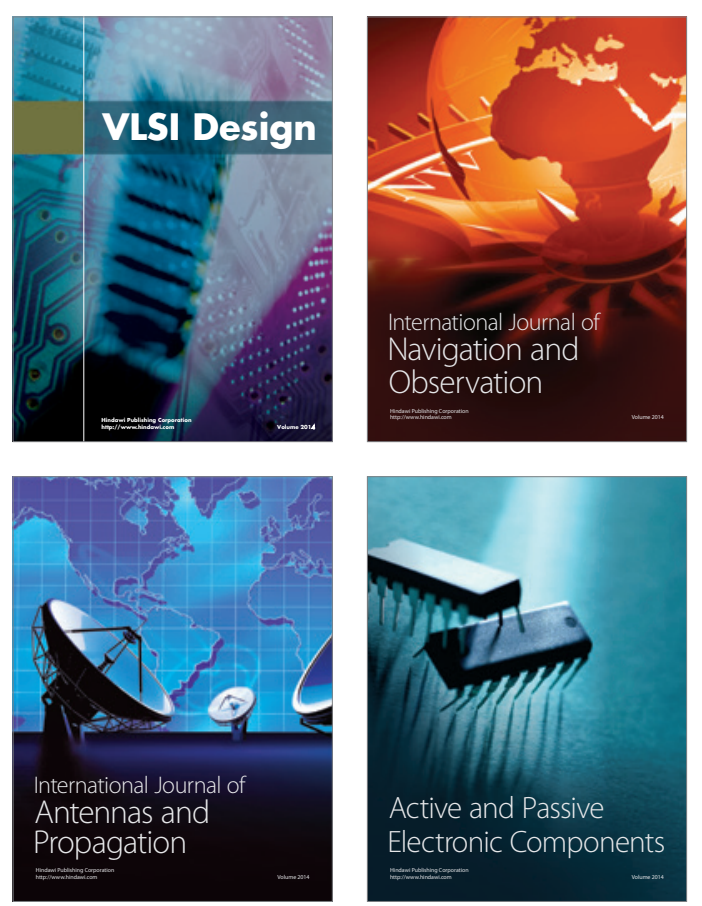
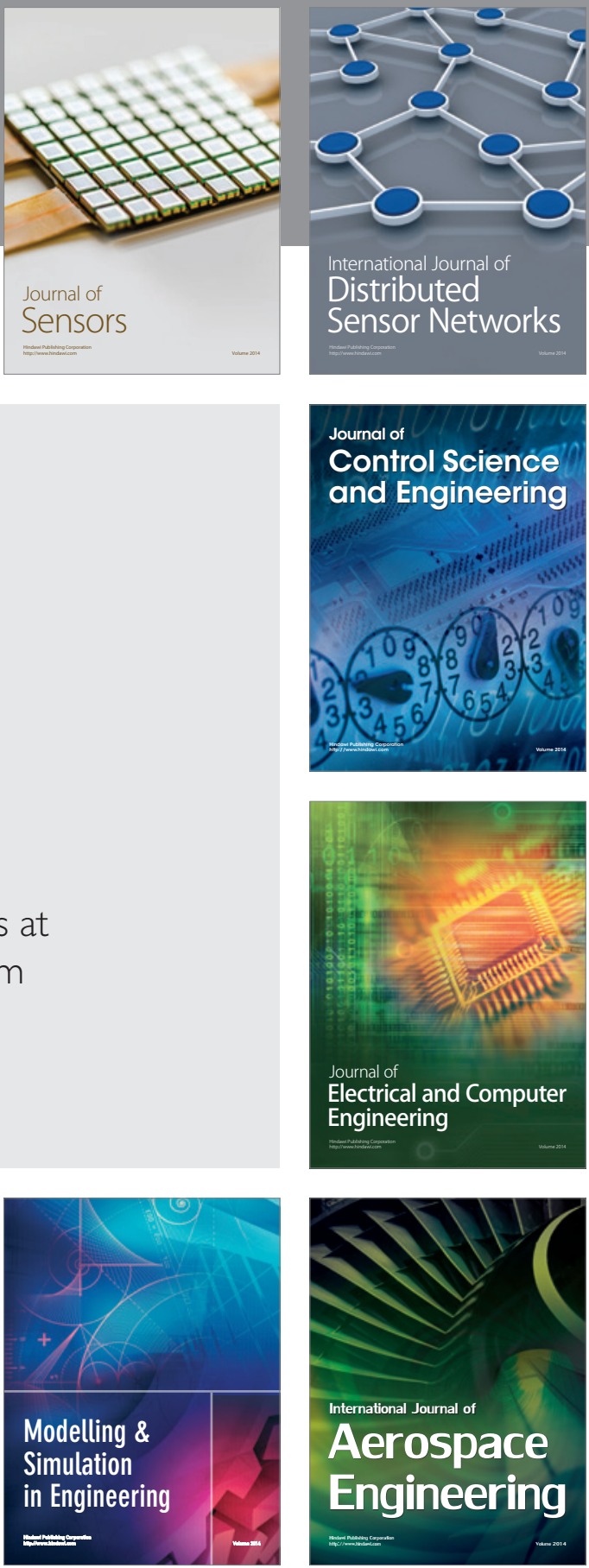

Journal of

Control Science

and Engineering
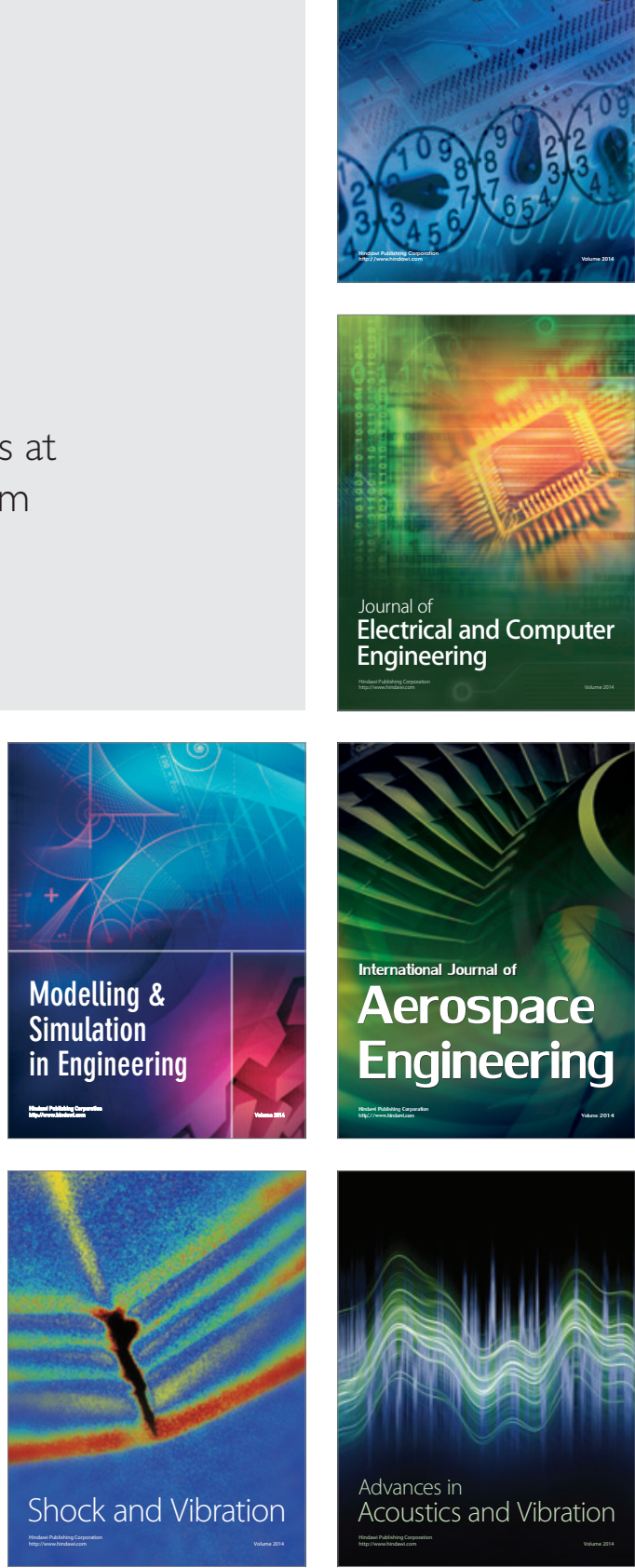